\title{
Historical Ecology and Ethnobiology: Applied Research for Environmental Conservation and Social Justice
}

\author{
Chelsey Geralda Armstrong ${ }^{1 *}$, James R. Veteto ${ }^{2}$ \\ Author addresses: ${ }^{1}$ Department of Archaeology, Simon Fraser University, 8888 University Drive, Burnaby, British Columbia, \\ V5A 1S6, Canada. ${ }^{2}$ Department of Anthropology and Sociology and Cherokee Studies Program, 106A McKee Building, \\ Western Carolina University, Cullowhee, North Carolina, 28723, USA. \\ *Corresponding Author: cdageralda@gmail.com
}

Received: January 11, 2015

Volume: 6(1):5-7

Published: March 6, 2015

(C) 2015 Society of Ethnobiology

\begin{abstract}
Historical ecology provides a research program and toolkit for applied interdisciplinary research in ethnobiology. With a focus on long-term changes in built environments and cultural landscapes, historical ecology emphasizes the need for scientific collaboration between disciplines for more relevant and applied academic research-particularly in service to environmental conservation and social justice.
\end{abstract}

Keywords: Historical ecology, ethnobiology, environmental change, applied ethnobiology, conservation, social justice

Historical ecology is a research program that focuses primarily on landscape as the unit of analysis and emphasizes the understanding of environmental change through deep time with an eye toward application in the present. By extending the timescale of landscape change, it is possible to create a more historically situated understanding of socioenvironmental interactions and patterns. Such patterns can be used to help inform and initiate environmental conservation and social justice.

Since the early 1990s, historical ecology has been undertaken in various global contexts by ecologists, biologists, archaeologists, and anthropologists. Crumley and Balée have been the most visible advocates of historical ecology through their respective work in France and the Amazon (Balée 2013; Crumley 1994). Their unique but complimentary approaches to historical ecology-Crumley trained in archaeology and Balée in cultural anthropologyargue: (1) nearly all landscapes on earth have been affected by humans to differing degrees; (2) both human and natural phenomena that physically manifest in landscapes or immaterially in cultural memory can be studied as an integrative whole; and (3) knowledge of human-land use and change through time can and should be applied to contemporary issues (e.g., global climate change, Indigenous sovereignty). These foci contribute to and reinforce two interrelated paradigm shifts in contemporary anthropology and geology: the 'ontological turn' in the social sciences that challenges Western nature-culture dualisms and sees humans and landscapes as inseparable and interrelated wholes (Latour 2014); and increasing support for geological re-classification of the current epoch as the 'Anthropocene' in recognition of the keystone role that humans play in socioecological earth systems (e.g. Zalasiewicz et al. 2011).

The applied focus is likely the most broadly relevant aspect of historical ecology and provides fertile cross-linkages with ethnobiology. In Wolverton's (2013) conceptualization of 'Ethnobiology 5,' he calls for ethnobiologists to communicate the relevance of their research to help solve contemporary socioenvironmental issues. In the historical ecology research program, anthropologists are encouraged to broaden their research of local or Indigenous knowledge by including ethnohistoric data (e.g. Nabhan 2007); or by showing cultural memory, symbolism, and culinary practices are as important to agrobiodiversity conservation as official programs (e.g. Veteto and Welch 2013). In the field of archaeology, historical ecology allows scholars to make their research more relevant by contributing to contemporary environmental issues (Balée and Erickson 2006) and providing, for example, long-term zooarchaeological data for the reassessment of ecological baselines (McKechnie et al. 2014).

Ongoing and more classic research demonstrates how ethnobiologists, environmental anthropologists, 
and archaeologists are applying historical ecology to contemporary environmental issues. Fairhead and Leach's (1996) groundbreaking work showed that Indigenous land-use strategies in a West African forest-savannah mosaic create forest islands rather than furthering deforestation (as previously assumed by scientists, forest ecologists, and conservationists), contributing policy recommendations of significant importance to both environmental conservation and social justice. Welch et al. (2013) have provided evidence for reversing assumptions of both development practitioners and conservationists in Central Brazil, using combined ethnographic and historical ecological data to show that Indigenous burning practices in a fire-adapted cerrado biome are significantly more conducive to forest stability and vegetation recovery than fire suppression and agribusiness expansion. A historical ecology research program in Peru utilized archaeological methods (pollen and soil analyses) to document relict agricultural features such as terraces, canals, and raised fields that exhibited excellent soil quality, good drainage, and buffers to frost risk (Erickson 1998). Archaeologists, agronomists, and communications experts subsequently worked with descendant communities to rehabilitate farming practices-based on insights from ancient agriculture-and their results proved to be more sustainable compared to contemporary Europeanstyle farms after only a few seasons. In another important case study, archaeologists and paleoecologists (Szpak et al. 2012) have used isotopic and zooarchaeological data (ca. 5200 years BP - AD 1900) to better understand the foraging ecology and historical range of locally extinct sea otters and help inform re-introduction programs on the Pacific Northwest Coast of North America.

Human health in Indigenous and local communities is intimately connected to the health of the environment and is another domain where historical ecology and ethnobiology are making significant contributions. The restoration or reinvigoration of sustainable cultural landscapes has had positive impacts on social well-being worldwide. Barthel et al. (2013) combine social memory, traditional ecological knowledge, landscape features, and local environmental fluctuations to argue that land-sharing (instead of land-sparing) is a key variable for preserving biocultural diversity and promoting food sovereignty in communities across Europe. A historical ecology orientation also informed experimental research that shows how anthropogenic non-Western management in ancient intertidal terraces and clam gardens resulted in clam density and overall biomass increases (Groesbeck et al. 2014). This work effectively demonstrates that viable food production and sustainable ecosystems can be simultaneously achieved, both in the past and (hopefully) in the present and future. Furthermore, such research demonstrates that First Nations communities have had long-term positive dialectical effects on contemporary (previously considered 'wild') ecosystems, providing evidence that can help Indigenous people assert rights and access to traditional landscapes in the context of current sociopolitical realities.

To date, historical ecology has been underutilized by ethnobiologists as a productive research program with notable exceptions (e.g. Balée 2013). This may be a result of the lack of exposure historical ecology receives in academia (it is often taught, if at all, as a segment or sub-unit of advanced courses in geography, anthropology, and ecology). We can envision future and ongoing (e.g. Human Ecodynamics Research Center-HERC; Integrated History and Future of People on Earth-IHOPE; Resilience in East African Landscapes-REAL) long-term historical ecology projects that combine the strengths of cultural anthropology, archaeology, and biology/ ecology in a unifying ethnobiological approach. This approach has the potential to further expand our research into the applied realm, contributing to a future that is more environmentally sustainable and socially just.

\section{References Cited}

Balée, W. 2013. Cultural Forests of the Amazon: A

Historical Ecology of People and Their Landscapes. University of Alabama Press, Tuscaloosa, AL.

Balée, W. and C. Erickson, eds. 2006. Time and Complexity in Historical Ecology: Studies in the Neotropical Lowlands. Columbia University Press, New York, NY.

Barthel, S., C. L. Crumley, and U. Svedein. 2013. Biocultural Refugia: Combatting the Erosion of Diversity in Landscapes of Food Production. Ecology and Society 18:71. Doi: http://dx.doi.org/10.5751/ ES-06207-180471.

Crumley, C. L., ed. 1994. Historical Ecology: Cultural Knowledge and Changing Landscapes. School of American Research Press, Santa Fe, NM.

Erikson, C. 1998. Applied Archaeology and Rural Develop- 
ment: Archaeology's Potential Contribution to the Future. In Crossing Currents: Continuity and Change in Latin America, edited by M. Whiteford and S. Whiteford, pp. 34 -45. Prentice-Hall, Upper Saddle, NJ.

Fairhead, J., M. Leach. 1996. Misreading the African Landscape: Society and Ecology in a Forest-Savanna Mosaic. Cambridge University Press, Cambridge, UK.

Groesbeck, A. S., K. Powell, D. Lepofsky, and A. K. Salomon. 2014. Ancient Clam Gardens Increased Shellfish Production: Adaptive Strategies from the Past Can Inform Food Security Today. PLoS ONE 9(3): e91235. Doi: 10.1371/journal.pone.0091235.

Latour, B. 2014. Another Way to Compose the Common World. HAU: Journal of Ethnographic Theory 4:301-307. Doi: http://dx.doi.org/10.14318/hau4.1.016.

McKechnie, I., D. Lepofsky, M. L. Moss, V. L. Butler, T. J. Orchard, G. Coupland, F. Foster, M. Caldwell, and K. Lertzman. 2014. Archaeological Data Provide Alternative Hypotheses on Pacific Herring (Clupea pallasii) Distribution, Abundance, and Variability. Proceedings of the National Academy of Sciences 111:807-816. Doi:10.1073/ pnas.1316072111.

Nabhan, G. P. 2007. Agrobiodiversity Change in Saharan Desert Oasis, 1919-2006: Historic Shifts in Tasiwit (Berber) and Bedouin Crop Inventories of Siwa, Egypt. Economic Botany 61:31-42. Doi: 10.1663/0013-0001(2007) 61[31:ACIASD]2.0.CO;2.

Szpak, P., T. J. Orchard, I. McKechnie, and D. R. Gröcke. 2012. Historical Ecology of Late Holocene Sea Otters (Enhydra lutris) from Northeastern British Columbia: Isotopic and Zooarchaeological Perspectives. Journal of Archaeological Science 39:1553-1571. Doi:10.1016/ j.jas.2011.12.006.

Veteto, J. R., and K. Welch. 2013. Food from the Ancestors: Documentation, Conservation, and Revival of Eastern Cherokee Heirloom Plants. In Seeds of Resistance/ Seeds of Hope: Place and Agency in the Conservation of
Biodiversity, edited by V. D. Nazarea, R. E. Rhoades, and J. E. Andrews-Swann, pp. 65-84. University of Arizona Press, Tucson, AZ.

Welch, J. R., E. S. Brondízio, S. S. Hetrick, and C. E. A. Coimbra Jr. 2013. Indigenous Burning as Conservation Practice: Neotropical Savanna Recovery Amid Agribusiness Deforestation in Central Brazil. PLoS One 8:e81226. Doi:10.1371/journal.pone.0081226.

Wolverton, S. 2013. Ethnobiology 5: Interdisciplinarity in an Era of Rapid Environmental Change. Ethnobiology Letters 4:21-25. Doi: http://dx.doi.org/10.14237/ ebl.4.2013.11.

Zalasiewicz, J., M. Williams, A. Haywood, and M. Ellis. 2011. The Anthropocene: A New Epoch of Geological Time? Philosophical Transactions of the Royal Society $A$ 369:835-841. Doi:10.1098/rsta.2010.0339.

\section{Biosketches}

Chelsey Geralda Armstrong is a Ph.D. student in the Department of Archaeology at Simon Fraser University. Her work focuses on ecological archaeology and paleoethnobotany, ancient and modern plant genetics, and Indigenous knowledge in the Pacific Northwest and Eastern Great Lakes regions.

James R. Veteto is Assistant Professor and Cherokee Studies program faculty member in the Department of Anthropology and Sociology at Western Carolina University. He is recent past president of Culture \& Agriculture, Executive Director of the Appalachian Institute for Mountain Studies, and Research Associate at the Botanical Research Institute of Texas. His research is focused on three interrelated themes: sustainable agriculture, biocultural diversity, and food and culture; culture and climate change; and alternative political ecologies. 